\title{
Triage of acute onset chest pain: now a biochemical rule-out test?
}

\author{
'SJ Wilson, ${ }^{2} \mathrm{P}$ Bloomfield, ${ }^{3} \mathrm{PO}$ Collinson \\ ${ }^{1}$ Cardiology Registrar; ${ }^{2}$ Consultant Cardiologist, Royal Infirmary of Edinburgh, Scotland, UK; ${ }^{3}$ Senior Lecturer/Reader, Departments of \\ Cardiology and Clinical Blood Sciences, St George's Hospital and Medical School, London, UK
}

The management of coronary disease has moved forward with the application of more sensitive blood biomarkers for early detection alongside more structured symptom assessment, examination and serial ECG measures. However every episode of exertional chest pain isn't symptomatic coronary disease and given massive public awareness campaigns we now face a different management issue with undiagnosed chest pain sent as a 'rule-out' activity. These urgent referrals are often justified based on the management of the minority with unstable coronary disease without preliminary medical review or examination. Avoiding delay which is valuable in coronary patients may be irrelevant to the majority. The overall effectiveness of this pathway is unclear where the patient does not have coronary disease but also where superficial interpretation can be misleading through non-specificity. Do biomarker assays become the answer to every chest pain patient and has the basic assessment of the individual patient and a prior probability of disease no role to play? Does this activity represent a burden or an irrelevant dead end for non-coronary patients? We have asked for comment from two leading authorities on the evolving role and application of cardiac biomarker

Correspondence to $S$ Wilson, Department of Cardiology, Royal Infirmary of Edinburgh, Edinburgh EHI6 4SA, UK

tel. +44 (0)779 1677196 e-mail simonwilson3@nhs.net

Correspondence to PO Collinson, Departments of Cardiology and Clinical Blood Sciences, St George's Hospital and Medical School, London SWI7 ORE, UK

tel. +44 (0)208 7255934 e-mail technologies in managing this considerable and common clinical dilemma.

Paul.Collinson@stgeorges.nhs.uk

KEYWORDS Troponin, cardiac troponin T, cardiac troponin I, chest pain, triage

DECLARATION OF INTERESTS No conflict of interests declared.

\section{The exclusion of acute chest pain by biochemical markers will never be possible}

\author{
SJ Wilson, P Bloomfield
}

Chest pain is a major burden on healthcare resources in the UK, with the potential for significant morbidity and mortality. It is one of the most common referrals to hospital, accounting for around 5\% of presentations to the Emergency Department and one-third of unplanned admissions. ${ }^{1,2}$ In medicine, the traditional approach to assessment has been careful history taking and physical examination, formulation of a differential diagnosis, and the application of investigations to establish the diagnosis. Assessment of chest pain can be difficult, with a wide differential diagnosis including potentially life-threatening conditions. Symptoms and clinical signs are inadequate discriminators in many patients such that biomarkers are already heavily relied upon in some instances. It is proposed that the traditional medical approach to assessment has become redundant. That is, a more direct and streamlined approach can be adopted by utilising ever improving biomarkers as a rule-out test. This is clearly not possible for all causes of chest pain. Suspected pathologies such as pneumothorax or aortic dissection for example will inevitably need radiological evaluation. Furthermore, despite newer high sensitivity D-dimer assays, diagnosis of pulmonary embolism (PE) remains reliant on clinical appraisal and pre-test probability; a normal D-dimer cannot reliably exclude $\mathrm{PE}$ in intermediate/high risk individuals. ${ }^{3-5}$ On the other hand, suspected acute coronary syndrome (ACS) which is the cause of greatest burden in chest pain assessment has biomarkers that would appear much more promising.

\section{ACUTE CORONARY SYNDROME}

A substantial proportion of patients presenting with chest pain have suspected acute coronary syndrome. Of those shown to have ACS only a quarter are ST elevation myocardial infarction (STEMI), with the majority either non-ST elevation myocardial infarction (NSTEMI) or unstable angina (UA). ${ }^{6}$ Individuals with NSTEMI or UA may be at considerable risk but the diagnosis is often difficult on clinical or electrocardiogram (ECG) results alone. Prognosis can be improved by early identification and treatment. Dual antiplatelet therapy such as aspirin and clopidogrel or prasugrel, and percutaneous coronary intervention have been shown to reduce the risk of future coronary thrombosis, myocardial infarction (MI) and death. The UK Registry reports the six-month mortality for non-ST elevation 
acute coronary syndromes as 7.3\%.7 However if the diagnosis of ACS is missed, prognosis may be significantly worsened with evidence of a two- to three-fold increase in short term mortality. ${ }^{8-12}$ The measurement of biomarkers, in particular troponin, has revolutionised ACS assessment.

\section{TROPONIN}

Troponin is a structural protein released into the circulation from myocyte necrosis with the cardiac isoforms TnT and Tnl virtually specific to cardiac muscle. ${ }^{13}$ Detection of troponin in blood is an exquisitely sensitive marker of myocardial cell death, and therefore MI. Furthermore, higher levels of troponin are associated with increased thrombus burden within the coronary arteries, greater complexity of coronary artery lesions and reduced perfusion of the coronary bed. ${ }^{14-15}$ Troponin elevation therefore identifies patients who benefit from more potent anti-platelet/anticoagulant and early invasive strategies. ${ }^{16}$ Perhaps even more important in considering a rule-out test for ACS, the value of troponin extends beyond diagnostic and therapeutic decision making. Troponin is a strong and independent marker of future adverse events and prognosis. ${ }^{16-19}$

Current controversies centre on the absolute level of troponin that is necessary to be detected in blood to diagnose $\mathrm{Ml}$ or exclude risk. Additionally, whether the measurement of very small amounts of the specific protein will enable us to detect myocardial ischaemia or improve outcomes is unclear. The current European/ American definition of $\mathrm{Ml}$ is a rise in troponin above the 99th percentile of a healthy reference population in the clinical context of myocardial ischaemia. ${ }^{20}$ To prevent misdiagnosis, it is recommended assays achieve this with a coefficient variation $(\mathrm{CV})$ of less than $10 \%$. Across the UK, few assays in practice are able to realise this. Instead, laboratories have to adopt a cut-off above the 99th percentile to maintain acceptable precision. Mills et al. investigated the effect of adopting the 99th percentile (0.012 micrograms per litre $[\mu \mathrm{g} / \mathrm{L}])$ of their $\mathrm{Tnl}$ assay instead of the diagnostic limit $(0.05 \mu \mathrm{g} / \mathrm{L}, 10 \% \mathrm{CV})$ in the assessment of suspected ACS. ${ }^{18}$ Diagnosis of MI would have increased from $36 \%$ to $53 \%$, a relative increase of $47 \%$. Instead only one-third of these 'troponin negative' patients were labelled as ACS, presumably UA, or referred to cardiology due to clinical suspicion. Consequently, a number of patients with a small but nevertheless prognostically significant troponin elevation above the recommended 99th percentile but below current diagnostic limits are already being missed. Present assays are not sensitive enough to meet current recommendations or to be considered appropriate as a rule-out test. Furthermore, such a strategy would in our opinion compound the error by discouraging proper clinical assessment.
TABLE I Non-acute coronary syndrome causes of troponin elevation

\begin{tabular}{|l|l|}
\hline Dynamic & Chronic \\
\hline Pulmonary embolism & End-stage renal failure \\
\hline Perimyo/myocarditis & Chronic heart failure \\
\hline Acute heart failure & Heart transplant \\
\hline Aortic dissection & Pulmonary hypertension \\
\hline Sepsis/critical illness & Left ventricular hypertrophy \\
\hline Cardiac contusion & Chronic stable angina \\
\hline $\begin{array}{l}\text { Acute ischaemic or } \\
\text { heamorrhagic stroke }\end{array}$ & $\begin{array}{l}\text { Infiltrative disorders } \\
\text { e.g. amyloid }\end{array}$ \\
\hline Chemotherapy & \\
\hline
\end{tabular}

In the near future, newer high and ultra sensitive troponin assays will overcome this difficulty. However given their ability to study troponin down to the very low physiological levels seen in healthy individuals, the sensitivity in detecting MI will no longer depend on assay capability rather the cut-off employed.This is particularly significant considering these new assays have substantiated that in fact any degree of troponin rise portends increased risk and an adverse prognosis. ${ }^{21-23}$ Therefore the 99th percentile cut-off, which is statistically derived rather than evidence based, may not be appropriate. Whether the prognostic benefits from current early invasive and potent anti-platelet/anticoagulant therapeutic strategies will extend to these lowest of troponin elevations is unknown. In any case, further research is required to determine evidence-based thresholds particularly before any greater reliance on troponin is made. It may be there is no universal cut-off, instead thresholds may vary according to the information required, whether diagnostic, prognostic or therapeutic.

In considering a lower troponin cut-off, which may be appropriate particularly for a rule-out test, the overall clinical impact and practicalities must also be considered. They have yet to be fully understood at the 99th percentile let alone beyond. At lower troponin concentrations there is an escalating prevalence of nonACS causes of troponin elevation.This causes progressive difficulty in troponin interpretation for a growing number of 'positive' individuals and increases the risk of misinterpretation (Table I). ${ }^{24-26}$ It may be argued this is irrelevant, as any troponin rise no matter what the underlying cause is significant and therefore worthwhile detecting. While this is true, the value of such a diagnosis and allocation of resources in doing so may be limited if the risk cannot be modified as a result e.g. chronic heart failure or left ventricular hypertrophy. ${ }^{17}$

Another difficulty is biological variability. Serial troponin testing can be helpful in ACS diagnosis particularly with lower troponin concentrations.A dynamic rise occurs to a greater degree with MI. At the 99th percentile, the 
recommendation is a rise or fall in troponin of at least $20 \%{ }^{27}$ However, with progressively lower troponin levels the influence of biological variability in an individual's baseline troponin steadily increases. Thus, at levels below the 99th percentile a change in troponin greater than $50 \%$ or perhaps higher may be necessary to be sure a clinically significant rise has occurred..$^{28-29}$ Similarly the precision of healthy reference populations used to establish normal troponin values will be ever more decisive, such that sex, race and age may need to be considered. In fact, existing reference population ranges for many of the assays may overestimate the true 99th percentile for various subgroups, so that assay performance appears more favourable. It is clear that further research is required before lower cut-offs can be considered. This will include determining what constitutes a significant dynamic troponin rise for a given concentration and healthy reference ranges for differing individuals. Perhaps more importantly, the benefit of early Ml detection or safe discharge of some individuals by lowering the cut-off needs to be established against the burden of increased identification of nonACS, perhaps non-modifiable causes.

\section{UNSTABLE ANGINA, MYOCARDIAL ISCHAEMIA AND OTHER BIOMARKERS}

An increase in plasma troponin has become synonymous with ACS despite being a poor marker, if at all, of myocardial ischaemia and therefore UA as currently defined. There is debate whether troponin release can occur from reversible myocardial ischaemia due to egress from the small amount contained in the cardiomyocyte cytoplasmic pool. ${ }^{30-32}$ Alternatively this troponin elevation may reflect patchy myocyte necrosis too small to be detected by current imaging techniques. Regardless, troponin is an inadequate marker of myocardial ischaemia and UA particularly as a rule-out test. ${ }^{23,33}$ Venge et al. demonstrated that in ACS, to achieve a greater than $90 \%$ negative predictive value for myocardial ischaemia using troponin, the cut-off would have to be at the 50th percentile. ${ }^{23}$ At this level, $50 \%$ of normal patients would also have a positive test. This is highly impractical.

Detecting myocardial ischaemia before irreversible necrosis ensues is obviously advantageous and essential to a rule-out test which includes UA. Several alternative biomarkers of myocardial ischaemia have been proposed of which ischaemia modified albumin (IMA) and hearttype fatty acid-binding protein $(\mathrm{H}-\mathrm{FABP})$ are the most promising. Ischaemia modified albumin in particular appeared hopeful, with reasonable sensitivity and negative predictive value for early detection of ACS as well as providing additional diagnostic and prognostic information to troponin. ${ }^{34-37}$ It is the only biomarker for myocardial ischaemia to have been approved by the US Federal Drugs Administration for clinical use. However both markers are hindered by a lack of cardio-specificity and sufficient clinical evidence, and the IMA test was recently withdrawn from commercial sale. It may be that a multi-marker approach is the future. Biomarkers such as $\mathrm{N}$-terminal pro b-type natriuretic peptide (NT-proBNP) or high sensitivity C-reactive protein (hsCRP) identify ACS patients at increased risk of death, irrespective if troponin is elevated or not. ${ }^{38} \mathrm{~A}$ metaanalysis showed a triple rule-out test (troponin, IMA, ECG) had a negative predictive value of $97 \%$ for ACS and 94.5\% for longer term outcomes although the added value of IMA was not clear. ${ }^{39}$ Further studies are required to understand if and how these 'novel' markers can be useful in clinical practice.

\section{CONCLUSIONS}

Troponin is the most validated biomarker in clinical use with regard to ACS but over-dependence must be avoided. It does not reliably exclude myocardial ischaemia and therefore UA and current assays are not sensitive enough to meet the recommended 99th percentile cut-off for MI. Furthermore, an evidencebased cut-off particularly regarding risk has yet to be established. In considering a lower troponin threshold, the overall clinical benefit has to be determined and difficulties with assay imprecision, biological variability and appropriate reference populations overcome. Utilising troponin as a rule-out test may have a negative impact by discouraging proper assessment. A patient's presenting symptoms of chest pain might be falsely diagnosed as an ACS. Thus an elderly lady with a new onset of atrial fibrillation associated with longstanding hypertensive heart disease might present with palpitation and have a 'positive troponin'. This increase would be related to arrhythmia and hypertensive heart disease not ACS. However she might unnecessarily be given dual antiplatelet and anticoagulant treatment and be subjected to invasive coronary angiography, a procedure with some risk to the patient and considerable cost to the Health Service. Similarly a middle-aged woman with a small pulmonary embolism might present with chest pain, minor ECG changes and a positive troponin. If labelled ACS she would receive antiplatelet therapy and possibly coronary angiography, when a careful assessment would have revealed the accurate diagnosis and initiation of the correct potentially lifesaving treatment.Alternatively, patients whose symptoms of chest pain were related to underlying coronary disease but who had no rise in troponin due to lack of assay sensitivity or myocardial ischaemia, may be falsely reassured and not referred for further investigation or given important secondary preventive medication. 
The exclusion of acute chest pain by biochemical markers will never be possible considering the range of potentially life-threatening aetiologies. In suspected ACS we believe that sensitive markers such as plasma troponin are an extremely important and useful adjunct to diagnosis and assessing prognosis. Improvement in current assays and development of alternative biomarkers will increasingly support but never replace a careful history and clinical assessment of patients.

\section{REFERENCES}

I Ruigomez A, Rodriguez LA, Wallander MA et al. Chest pain in general practice: incidence, comorbidity and mortality. Fam Pract 2006; 23:I67-74. http://dx.doi.org/I0.1093/fampra/cmi I 24

2 Skinner JS, Smeeth L, Kendall JM et al. NICE guidance. Chest pain of recent onset: assessment and diagnosis of recent onset chest pain or discomfort of suspected cardiac origin. Heart 2010; 96:974-8. http://dx.doi.org/10.1 I36/hrt.2009.190066

3 Hammond CJ, Hassan TB. Screening for pulmonary embolism with a D-dimer assay: do we still need to assess clinical probability as well? J R Soc Med 2005; 98:54-8.http://dx.doi.org/ / 0. I258/jrsm.98.2.54

4 British Thoracic Society. British Thoracic Society guidelines for the management of suspected acute pulmonary embolism. Thorax 2003; 58:470-83. http://dx.doi.org/10.1 I36/thorax.58.6.470

5 Kabrhel C. Outcomes of high pretest probability patients undergoing d-dimer testing for pulmonary embolism: a pilot study J Emerg Med 2008; 35:373-7. http://dx.doi.org/10.1016/j. jemermed.2007.08.070

6 Loria V, Leo M, Biasillo $\mathrm{G}$ et al. Biomarkers in acute coronary syndrome. Biomark Insights 2008; 3:453-68.

7 Collinson J, Flather MD, Fox KA et al. Clinical outcomes, risk stratification and practice patterns of unstable angina and myocardial infarction without ST elevation: prospective registry of acute ischaemic syndromes in the UK (PRAIS-UK). Eur Heart $J$ 2000; 2 I:1450-7. http://dx.doi.org/I0.1053/euhj.1999.1995

8 Heidenreich PA, McClellan M. Trends in treatment and outcomes for acute myocardial infarction: 1975-1995. Am J Med 2001; I I0:165-74. http://dx.doi.org//0.1016/S0002-9343(00)007I2-9

9 Montalescot G,Wiviott SD, Braunwald E et al. Prasugrel compared with clopidogrel in patients undergoing percutaneous coronary intervention for ST-elevation myocardial infarction (TRITON-TIMI 38): double-blind, randomised controlled trial. Lancet 2009; 373;723-3I. http://dx.doi.org/I0.1016/S0 I40-6736(09)6044I-4

10 Lee TH, Goldman L. Evaluation of the patient with acute chest pain. N Engl J Med 2000; 342:I I87-95. http://dx.doi.org/I0.1056/ NEJM200004203421607

II Brieger D, Eagle KA, Goodman SG et al. Acute coronary syndromes without chest pain, an underdiagnosed and undertreated high-risk group: insights from the Global Registry of Acute Coronary Events. Chest 2004; 126:46I-9. http://dx.doi. org/10.1378/chest. I26.2.46I

12 Boersma E, Pieper KS, Steyerberg EW et al. Predictors of outcome in patients with acute coronary syndromes without persistent ST-segment elevation. Circulation 2000; 101:2557-67. http://dx.doi. org/I0.II6I/0I.CIR.I0I.22.2557

I3 Shave R, Dawson E, Whyte G et al. The cardiospecificity of thirdgeneration troponin CTNT assay after exercise-induced muscle damage. Med Sci Sports Exerc 2002; 34:65I-4. http://dx.doi. org/10.1097/00005768-200204000-000I4

14 Hamm CW, Heeschen C, Goldmann B et al. Benefit of abciximab in patients with refractory unstable angina in relation to serum troponin T levels. N Engl J Med 1999; 340:1623-9 http://dx.doi. org/I0.1056/NEJMI99905273402103

15 Wong GC, Morrow DA, Murphy S et al. Elevations in troponin T and $I$ are associated with abnormal tissue level perfusion: a TACTICS-TIMI 18 substudy. Circulation 2002; 106:202-7. http:// dx.doi.org/I0.II6I/0I.CIR.000002192I.14653.28

I6 Morrow DA, Cannon CP, Rifai $\mathrm{N}$ et al. Ability of minor elevations of troponins I and $\mathrm{T}$ to predict benefit from an early invasive strategy in patients with unstable angina and non-ST elevation myocardial infarction: results from a randomized trial. JAMA 200 I; 286:2405-12. http://dx.doi.org/I0.100I/jama.286.19.2405

17 Celik S, Giannitsis E, Wollert KC et al. Cardiac troponin T concentrations above the 99th percentile value as measured by a new high-sensitivity assay predict long-term prognosis in patients with acute coronary syndromes undergoing routine early invasive strategy. Clin Res Cardiol 201 I; 100:1077-85. http://dx.doi. org/I0.1007/s00392-0I I-0344-x

18 Mills NL, Lee KK, Denvir MA et al. Implications of lowering threshold of plasma troponin concentration in diagnosis of myocardial infarction: cohort study. BMJ 20I2; 344:el533. http:// dx.doi.org/10.1/36/bmj.el533

19 Lindahl B, Diderholm E, Lagerqvist B et al. Mechanisms behind the prognostic value of troponin $\mathrm{T}$ in unstable coronary artery disease: a FRISC II substudy. J Am Coll Cardiol 200I; 38:979-86. http://dx.doi.org/I0.1016/S0735-1097(0I)0150I-7

20 Thygesen K,Alpert JS,White HD. Universal definition of myocardial infarction. J Am Coll Cardiol 2007; 50:2173-95. http://dx.doi. org/10.1016/j.jacc.2007.09.0II

2I Eggers KM, Jaffe AS, Lind L et al.Value of cardiac troponin I cutoff concentrations below the 99th percentile for clinical decisionmaking. Clin Chem 2009; 55:85-92. http://dx.doi.org//0.1373/ clinchem.2007.101683

22 Body R, McDowell G, Carley S et al. Diagnosing acute myocardial infarction with troponins: how low can you go? Emerg Med J 2010; 27:292-6. http://dx.doi.org/I0.10 I6/j.jacc.2007.09.0I I

23 Venge P, Johnston N, Lindahl B et al. Normal plasma levels of cardiac troponin I measured by the high-sensitivity cardiac troponin I access prototype assay and the impact on the diagnosis of myocardial ischemia. J Am Coll Cardiol 2009; 54:I 165-72. http:// dx.doi.org/I0.1016/j.jacc.2009.05.05I

24 Korosoglou G, Lehrke S, Mueller D et al. Determinants of troponin release in patients with stable coronary artery disease: insights from CT angiography characteristics of atherosclerotic plaque. Heart 20I I; 97:823-3I. http://dx.doi.org/I0.II36/hrt.20I0.19320I

25 Ndrepepa G, Braun S, Mehilli J et al. Prognostic value of sensitive troponin $\mathrm{T}$ in patients with stable and unstable angina and undetectable conventional troponin. Am Heart J 201 I; I61:68-75. http://dx.doi.org/10.1016/j.ahj.2010.09.018

26 White HD. Pathobiology of troponin elevations: do elevations occur with myocardial ischaemia as well as necrosis? J Am Coll Cardiol 20I I; 58:2356.

27 Wu AH, Jaffe AS, Apple FS et al. National Academy of Clinical Biochemistry laboratory medicine practice guidelines: use of cardiac troponin and B-type natriuretic peptide or $\mathrm{N}$-terminal proB-type natriuretic peptide for etiologies other than acute coronary syndromes and heart failure. Clin Chem 2007; 53:208696. http://dx.doi.org// 0.1373/clinchem.2007.095679

28 Frankenstein $\mathrm{L}, \mathrm{Wu} \mathrm{AH}$, Hallermayer $\mathrm{K}$ et al. Biological variation and reference change value of high-sensitivity troponin $T$ in healthy individuals during short and intermediate follow-up periods. Clin Chem 20II; 57:1068-7I. http://dx.doi.org/I0.1373/ clinchem.2010.158964 
29 Jaffe AS, Apple FS. Refining our criteria: a critical challenge. Am J Clin Pathol 2009; |31:1|-3. http://dx.doi.org//0.1309/ AJCPFYDY7B2AYDZE

30 Chen Y, Serfass RC, Mackey-Bojack SM et al. Cardiac troponin T alterations in myocardium and serum of rats after stressful, prolonged intense exercise. J Appl Physiol 2000; 88: 1749-55.

$31 \mathrm{Wu} \mathrm{AH}$, Ford L. Release of cardiac troponin in acute coronary syndromes: ischemia or necrosis? Clin Chim Acta 1999; 284:161-74. http://dx.doi.org/I0.1016/S0009-8981(99)00078-9

32 Sabatine MS, Morrow DA, de Lemos et al. Detection of acute changes in circulating troponin in the setting of transient stress test-induced myocardial ischaemia using an ultrasensitive assay: results from TIMI 35. Eur Heart J 2009; 30:162-9. http://dx.doi. org/I0.1093/eurheartj/ehn504

33 Reichlin T, Hochholzer W, Bassetti S et al. Early diagnosis of myocardial infarction with sensitive cardiac troponin assays. $\mathrm{N}$ Engl J Med 2009; 361:858-67. http://dx.doi.org//0.1056/ NEJMoa0900428

34 Lee YW, Kim HJ, Cho YH et al. Application of albumin-adjusted ischemia modified albumin index as an early screening marker for acute coronary syndrome. Clin Chim Acta 2007; 384:24-7. http:// dx.doi.org/I0.1016/j.cca.2007.05.003

35 Roy D, Quiles J,Aldama $G$ et al. Ischemia modified albumin for the assessment of patients presenting to the emergency department with acute chest pain but normal or non-diagnostic 12-lead electrocardiograms and negative cardiac troponin T. Int J Cardiol 2004; 97:297-301. http://dx.doi.org//0.1016/j.jicard.2004.05.042
36 Sinha MK, Roy D, Gaze DC et al. Role of "Ischemia Modified Albumin", a new biochemical marker of myocardial ischaemia, in the early diagnosis of acute coronary syndromes. Emerg Med J 2004; 21:29-34. http://dx.doi.org/I0.II36/emj.2003.006007

37 Consuegra-Sanchez L, Bouzas-Mosquera A, Sinha MK et al. Ischemia-modified albumin predicts short-term outcome and I-year mortality in patients attending the emergency department for acute ischemic chest pain. Heart Vessels 2008; 23: 174-80. http:// dx.doi.org/I0.1007/s00380-007-I03I-8

38 Christenson RH. Preamble: National Academy of Clinical Biochemistry laboratory medicine practice guidelines for utilization of biomarkers of acute coronary syndromes and heart failure. Clin Biochem 2008; 41:208-9. http://dx.doi.org/10.1016/j. clinbiochem.2007.07.003

39 Peacock F, Morris DL, Anwaruddin S et al. Meta-analysis of ischemia-modified albumin to rule out acute coronary syndromes in the emergency department. Am Heart J 2006; 152:253-62. http://dx.doi.org/10.1016/j.ahj.2005.12.024

\section{Triage of acute onset chest pain is now a biochemical rule-out test}

\section{PO Collinson}

Triage: The assignment of degrees of urgency to wounds or illnesses to decide the order of treatment of a large number of patients or casualties.'

Patients with chest pain constitute the largest single category of patients attending emergency departments (ED) and admitted to hospitals in the UK. ${ }^{2}$ Although the electrocardiogram (ECG) is an excellent tool to select those patients who will benefit most significantly from revascularisation, it is a poor diagnostic test for acute myocardial infarction (AMI). When post-mortem studies are used as the ultimate 'gold standard' diagnosis, the ECG has a sensitivity of only $4|-6| \%{ }^{3,4}$ Similarly using a consensus final diagnosis based on all available clinical data, the diagnostic sensitivity of the ECG has been found to be $57 \% .^{5}$ Even in patients presenting with ST segment elevation, diagnostic accuracy for AMI is not $100 \%^{6}$ and confirmatory testing is required. The measurement of biochemical markers of myocardial injury, originally referred to as 'cardiac enzymes' and now referred to as cardiac biomarkers has been accepted as a necessity since the 1970s. Cardiac enzymes are included within the diagnostic criteria of the original World Health Organization (WHO) definition of myocardial infarction (MI). ${ }^{7}$

The differential diagnosis of patients presenting with acute chest pain is challenging. It has been a consistent finding that $3-7 \%$ of patients with AMI are inappropriately sent home from the ED. The challenge for the laboratory has been to deliver a rapid biomarkerbased confirmation or exclusion of significant myocardial injury. Although strategies based on rapid serial measurement of conventional cardiac enzymes such as creatine kinase $(C K)^{10}$ and its $M B$ isoenzyme 11 can significantly reduce time to confirmation or exclusion of $\mathrm{AMI}^{12}{ }^{2}$ neither of these tests are cardiac specific. The ability to measure the protein components of the cardiac contractile apparatus, the cardiac troponins cardiac troponin $\mathrm{T}(\mathrm{cTnT})^{13}$ and cardiac troponin I $(\mathrm{cTnl})^{14}$ represented a significant breakthrough in the field of cardiac biomarker measurement. The development of rapid automated immunoassays for cTnT and cTnl resulted in a paradigm shift in the ability of a laboratory to provide cardiac biomarker information as part of the workup of the chest pain patient.

Early studies demonstrated that measurement of cTnT and $\mathrm{cTnl}$ was superior to measurement of $\mathrm{CK}^{15}$ or CK-MB ${ }^{16}$ in patients with chest pain and suspected AMI. In particular, it was demonstrated that in patients where AMI had been ruled out by conventional testing, an elevated cTnT or cTnl diagnosed missed myocardial injury with an adverse prognosis. The demonstration that troponin elevations could be linked to treatment strategies ${ }^{17-19}$ was the final confirmation of the utility of these new biomarkers. It was shown that cTnT and cTnl were prognostic irrespective of the admission ECG. ${ }^{20}$ 
Very rapidly, measurement of $\mathrm{cTnT}$ and $\mathrm{cTnl}$ was incorporated into the recommendations of professional societies $^{21}$ and ultimately into the definition of AMI. ${ }^{22,23}$

Initially, triage using troponin was for confirmation of diagnosis in patients presenting with ST segment elevation and for the confirmation or exclusion of AMI where the initial presenting diagnosis was uncertain. In patients presenting without ST elevation, a simple dichotomous troponin based classification of AMI was utilised. It was recognised early on that there were a few other conditions apart from AMI, most significantly renal failure, where troponin elevation was seen. ${ }^{24}$ The sensitivity of the measurement technology used in the laboratory for cTnT and cTnl measurement has progressively improved. As a result, the range of conditions other than suspected ACS where troponin elevations are known to occur has increased. Troponin elevation outside the ACS population has led to the concept that troponin measurement is non-specific. This is untrue. Troponin elevation is $100 \%$ specific for myocardial injury. In those conditions where there is follow-up information available, it has been conclusively demonstrated that troponin elevation outside of the ACS population indicates an adverse prognosis. This is perhaps most vividly demonstrated for patients with chronic renal failure. In this group, the majority of the mortality is cardiac and is predicted by the presence of a detectable cardiac troponin. ${ }^{25}$ Troponin elevation in chronic renal failure patients is associated with evidence of diffuse myocardial injury. ${ }^{26,27}$

The current generation of troponin assays is able to measure troponin levels in healthy normal individuals. It has been shown that the presence of an elevated troponin above the reference interval, currently defined as the 99th percentile, is associated with other cardiac risk factors ${ }^{28}$ and with an increased risk of cardiac events such as $\mathrm{Ml}^{29,30}$ or risk of development of heart failure. ${ }^{31}$ The other advantage of these sensitive troponin assays is the ability to achieve diagnostic sensitivity equivalent to the previous assays within one to two hours of admission $^{32,33}$ and very likely to achieve $100 \%$ diagnostic sensitivity by three to six hours from presentation. ${ }^{34}$

The concept of triage originated in World War I with French doctors who were treating the battlefield wounded, based on concepts originally developed by Dominique Jean Larrey during the Napoleonic Wars. There were three categories:

- Those who are likely to live, regardless of what care they receive;

- Those who are likely to die, regardless of what care they receive;

- Those for whom immediate care might make a positive difference in outcome.
The modern ED environment is not perhaps as extreme as this (although it may feel that way to the ED physician) but the fundamental concept of triage remains risk stratification and effectiveness of intervention. In the chest pain population troponin is the ultimate triage test. In those presenting with ST segment elevation, troponin measurement on admission defines the highest risk group $^{20}$ and subsequent measurement confirms the diagnosis, although the management pathway is already assigned. In the remaining two ECG categories, chest pain with a non-diagnostic but abnormal ECG or those with a normal ECG, troponin measurement will categorise patients into high-risk or low-risk chest pain.

The ability of small elevations of troponin to predict outcome and the impact of evidence-based therapies has recently been illustrated in a prospective observational study. ${ }^{35}$ Following a six-month baseline observation period, the diagnostic discriminant for the diagnosis of AMI for cTnl was lowered from 200 nanograms per litre (ng/L) to $50 \mathrm{ng} / \mathrm{L}$. The impact of this change in threshold on diagnosis and prognosis was followed up during the subsequent six months. Patients with troponin in the range $50-200 \mathrm{ng} / \mathrm{L}$ had a $39 \%$ rate of death or recurrent $\mathrm{MI}$ at one year compared to $21 \%$ following reduction of the diagnostic threshold. This was accompanied by a significant increase in the number of patients with cTnl in the range $50-200 \mathrm{ng} / \mathrm{L}$ group treated with evidence-based cardiac interventions. In a further study the same team examined the outcome of patients with a cTnl in the range from the 99th percentile to the $10 \%$ coefficient of variation $(\mathrm{CV})$ cut point of the assay, I4-<50 ng/L. ${ }^{36}$ They found patients with a cTnl in this range were four times more likely to have had an adverse cardiac event than those with a cTnl </4 ng/L.

In the chest pain population, failure of troponin to increase defines outcome, irrespective of whether the patient has ACS. This triage can be achieved very rapidly. Two large studies, one a randomised controlled trial ${ }^{37}$ and the other an observational study, ${ }^{38}$ have shown that failure of troponin to increase during the two-hour period following admission defines a low-risk group which can be safely discharged. Triage of acute onset chest pain is now a biochemical rule-out test based on troponin because it is fast and accurate.

\section{REFERENCES}

I Oxford English Dictionary. Kindle ed. Oxford: Oxford University Press.

2 Goodacre S, Cross E, Arnold J et al. The health care burden of acute chest pain. Heart 2005; 91:229-30. http://dx.doi.org/I0.II36/ hrt.2003.027599

3 Zarling EJ, Sexton H, Milnor P Jr. Failure to diagnose acute myocardial infarction. The clinicopathologic experience at a large community hospital. JAMA 1983; 250:II77-8I. http://dx.doi. org/I0.100I/jama.I983.03340090033025 
4 McQueen MJ, Holder D, El-Maraghi NR. Assessment of the accuracy of serial electrocardiograms in the diagnosis of myocardial infarction. Am Heart J 1983; 105:258-61. http:// dx.doi.org/10.1016/0002-8703(83)90524-0

5 Brush JE Jr, Brand DA, Acampora D et al. Use of the initial electrocardiogram to predict in-hospital complications of acute myocardial infarction. N Engl J Med 1985; 312:1|37-4I. http:// dx.doi.org/10.1056/NEJMI 98505023/2/801

6 Topol EJ, Bates ER, Walton JA Jr et al. Community hospital administration of intravenous tissue plasminogen activator in acute myocardial infarction: improved timing, thrombolytic efficacy and ventricular function. J Am Coll Cardiol 1987; 10:1 173-7. http:// dx.doi.org/I 0.1016/S0735-1097(87)80 I I4-6

7 Nomenclature and criteria for diagnosis of ischemic heart disease. Report of the Joint International Society and Federation of Cardiology/World Health Organization task force on standardization of clinical nomenclature. Circulation 1979; 59:607-9. http://dx.doi.org//0.1/6I/0I.CIR.59.3.607

8 Pope JH, Aufderheide TP, Ruthazer R et al. Missed diagnoses of acute cardiac ischemia in the emergency department. $N$ Engl J Med 2000;342: I 63-70.http://dx.doi.org/I0.1056/NEJM20000420342I603

9 Collinson PO, Premachandram S, Hashemi K. Prospective audit of incidence of prognostically important myocardial damage in patients discharged from emergency department. BMJ 2000; 320:1702-5. http://dx.doi.org/10.1 I36/bmj.320.725I.1702

10 Collinson PO, Rosalki SB, Flather $M$ et al. Early diagnosis of myocardial infarction by timed sequential enzyme measurements. Ann Clin Biochem 1988; 25:376-82.

II Collinson PO, Rosalki SB, Kuwana T et al. Early diagnosis of acute myocardial infarction by CK-MB mass measurements. Ann Clin Biochem 1992; 29:43-7.

12 Collinson PO, Ramhamadamy EM, Stubbs PJ et al. Rapid enzyme diagnosis of patients with acute chest pain reduces patient stay in the coronary care unit. Ann Clin Biochem 1993; 30:17-22.

13 Katus HA, Remppis A, Looser S et al. Enzyme linked immuno assay of cardiac troponin $\mathrm{T}$ for the detection of acute myocardial infarction in patients. J Mol Cell Cardiol 1989; 21:1349-53. http:// dx.doi.org/10.1016/0022-2828(89)90680-9

14 Cummins B, Auckland ML, Cummins P. Cardiac-specific troponin-I radioimmunoassay in the diagnosis of acute myocardial infarction. Am Heart J 1987; II3:1333-44. http://dx.doi.org//0.1016/00028703(87)90645-4

15 Stubbs P, Collinson P, Moseley D et al. Prospective study of the role of cardiac troponin T in patients admitted with unstable angina. $B M J$ 1996; 313:262-4. http://dx.doi.org/10.1 I36/bmj.313.7052.262

$16 \mathrm{Hamm}$ CW, Ravkilde J, Gerhardt W et al. The prognostic value of serum troponin T in unstable angina. N Engl J Med 1992; 327: I 4650. http://dx.doi.org//0.1056/NEJMI99207/63270302

17 Lindahl B, Venge P, Wallentin L. Troponin T identifies patients with unstable coronary artery disease who benefit from long-term antithrombotic protection. Fragmin in Unstable Coronary Artery Disease (FRISC) Study Group. J Am Coll Cardiol 1997; 29:43-8. http://dx.doi.org/I0.1016/S0735-1097(96)00447-0

18 Boersma E, Harrington RA, Moliterno DJ et al. Platelet glycoprotein Ilb/llla inhibitors in acute coronary syndromes: a meta-analysis of all major randomised clinical trials. Lancet 2002; 359: I89-98. http:// dx.doi.org/I0.10I6/S0I40-6736(02)07442-1

19 Diderholm E, Andren B, Frostfeldt G et al. The prognostic and therapeutic implications of increased troponin $T$ levels and ST depression in unstable coronary artery disease: the FRISC II invasive troponin T electrocardiogram substudy. Am Heart J 2002; | 43:760-7. http://dx.doi.org//0.1067/mhj.2002.121733

20 Stubbs $P$, Collinson P, Moseley D et al. Prognostic significance of admission troponin $T$ concentrations in patients with myocardial infarction. Circulation 1996; 94:|29|-7.

2I Wu AH, Apple FS, Gibler WB et al. National Academy of Clinical Biochemistry Standards of Laboratory Practice: recommendations for the use of cardiac markers in coronary artery diseases. Clin Chem 1999; 45: I I04-21.http://dx.doi.org/I0.II6I/0I.CIR.94.6.129|
22 Myocardial infarction redefined - a consensus document of The Joint European Society of Cardiology/American College of Cardiology Committee for the redefinition of myocardial infarction. Eur Heart J 2000; 21:1502-13. http://dx.doi.org//0.1053/ euhj.2000.2305

23 Thygesen K, Alpert JS, White HD et al. Universal definition of myocardial infarction. Circulation 2007; | 16:2634-53. http://dx.doi. org/I0.1I6I/CIRCULATIONAHA.107.187397

24 Collinson PO, Hadcocks L, Foo $Y$ et al. Cardiac troponins in patients with renal dysfunction. Ann Clin Biochem 1998; 35:380-6.

25 Khan NA, Hemmelgarn BR, Tonelli $M$ et al. Prognostic value of troponin $\mathrm{T}$ and I among asymptomatic patients with end-stage renal disease: a meta-analysis. Circulation 2005; I I2:3088-96. http:// dx.doi.org/I0.1 I6I/CIRCULATIONAHA.105.560I28

26 Sharma R, Gaze DC, Pellerin D et al. Cardiac structural and functional abnormalities in end stage renal disease patients with elevated cardiac troponin T. Heart 2006; 92:804-9. http://dx.doi. org/l0.1/36/hrt.2005.069666

27 deFilippi CR, Thorn EM, Aggarwal M et al. Frequency and cause of cardiac troponin $T$ elevation in chronic hemodialysis patients from study of cardiovascular magnetic resonance. Am J Cardiol 2007; 100:885-9. http://dx.doi.org//0.1016/j.amjcard.2007.04.028

28 Collinson PO, Heung YM, Gaze D et al. Influence of population selection on the 99th percentile reference value for cardiac troponin assays. Clin Chem 2012; 58:219-25. http://dx.doi. org/I0.1373/clinchem.20II.17I082

29 Zethelius B, Johnston N, Venge P. Troponin I as a predictor of coronary heart disease and mortality in 70-year-old men: a community-based cohort study. Circulation 2006; II3:107I-8. http://dx.doi.org// 0.1 I6I/CIRCULATIONAHA.105.570762

30 de Lemos JA, Drazner MH, Omland T et al. Association of troponin $T$ detected with a highly sensitive assay and cardiac structure and mortality risk in the general population. JAMA 2010; 304:2503-12. http://dx.doi.org/I0.1001/jama.2010.1768

31 deFilippi CR, de Lemos JA, Christenson RH et al. Association of serial measures of cardiac troponin $T$ using a sensitive assay with incident heart failure and cardiovascular mortality in older adults. JAMA 2010;304:2494-502.http://dx.doi.org/I0.100I/jama.2010.1708

32 Melanson SE, Morrow DA, Jarolim P. Earlier detection of myocardial injury in a preliminary evaluation using a new troponin I assay with improved sensitivity. Am J Clin Pathol 2007; I 28:282-6. http://dx.doi. org/I0.1309/Q9W5HJTT24GQCXXX

33 Reichlin T, Hochholzer W, Bassetti $S$ et al. Early diagnosis of myocardial infarction with sensitive cardiac troponin assays. $N$ Engl JMed 2009;361:858-67.http://dx.doi.org//0.1056/NEJMoa0900428

34 Keller T, Zeller T, Ojeda F et al. Serial changes in highly sensitive troponin I assay and early diagnosis of myocardial infarction. JAMA 2011; 306:2684-93. http://dx.doi.org/10.100I/jama.20II.1896

35 Mills NL, Churchhouse AM, Lee KK et al. Implementation of a sensitive troponin I assay and risk of recurrent myocardial infarction and death in patients with suspected acute coronary syndrome. JAMA 201I; 305:1210-6. http://dx.doi.org//0.100I/ jama.20II.338

36 Mills NL, Lee KK, McAllister DA et al. Implications of lowering threshold of plasma troponin concentration in diagnosis of myocardial infarction: cohort study. BMJ 20I2; 344:el533. http:// dx.doi.org/10.1136/bmj.el533

37 Goodacre SW, Bradburn M, Cross E et al. The Randomised Assessment of Treatment using Panel Assay of Cardiac Markers (RATPAC) trial: a randomised controlled trial of point-of-care cardiac markers in the emergency department. Heart 2011; 97:190-6. http://dx.doi.org//0.1136/hrt.2010.203166

38 Than M, Cullen L, Reid CM et al. A 2-h diagnostic protocol to assess patients with chest pain symptoms in the Asia-Pacific region (ASPECT): a prospective observational validation study. Lancet 201 I; 377:1077-84. http://dx.doi.org// 0.1016/S0 I40-6736(II)60310-3 